\title{
Prognostic Biomarkers in Early-stage Gastric Adenocarcinoma Treated With Adjuvant Chemoradiotherapy
}

\author{
EIRINI PECTASIDES ${ }^{1 *}$, IOANNIS CHATZIDAKIS ${ }^{2 *}$, VASSILIKI KOTOULA $^{3,4}$, \\ GEORGIA-ANGELIKI KOLIOU ${ }^{5}$, KYRIAKI PAPADOPOULOU ${ }^{4}$, ELENI GIANNOULATOU ${ }^{6,7}$, \\ VASILIOS G. GIANNOUZAKOS ${ }^{8}$, MATTHEOS BOBOS ${ }^{4}$, CHRISTOS PAPAVASILEIOU $^{9}$, \\ SOFIA CHRISAFI ${ }^{4}$, AIKATERINI FLOROU ${ }^{2}$, DIMITRIOS PECTASIDES ${ }^{2}$ and GEORGE FOUNTZILAS ${ }^{4,10,11}$ \\ ${ }^{1}$ Department of Medical Oncology, Dana Farber Cancer Institute, Boston, MA, U.S.A.; \\ ${ }^{2}$ Second Department of Internal Medicine, Propaedeutic, Oncology Section, \\ National and Kapodistrian University of Athens, University General Hospital Attikon, Athens, Greece; \\ ${ }^{3}$ Department of Pathology, Aristotle University of Thessaloniki, \\ School of Health Sciences, Faculty of Medicine, Thessaloniki, Greece; \\ ${ }^{4}$ Laboratory of Molecular Oncology, Hellenic Foundation for Cancer Research/Aristotle \\ University of Thessaloniki, Thessaloniki, Greece; \\ ${ }^{5}$ Section of Biostatistics, Hellenic Cooperative Oncology Group, Athens, Greece; \\ ${ }^{6}$ Bioinformatics and Systems Medicine Laboratory, \\ Victor Chang Cardiac Research Institute, Darlinghurst, NSW, Australia; \\ ${ }^{7}$ The University of New South Wales, Kensington, NSW, Australia; \\ ${ }^{8}$ Department of Radiation Therapy, Papageorgiou Hospital, Aristotle University of Thessaloniki, \\ School of Health Sciences, Faculty of Medicine, Thessaloniki, Greece; \\ ${ }^{9}$ Surgical Department, Papageorgiou Hospital, Aristotle University of Thessaloniki, \\ School of Health Sciences, Faculty of Medicine, Thessaloniki, Greece; \\ ${ }^{10}$ Aristotle University of Thessaloniki, Thessaloniki, Greece; \\ ${ }^{11}$ German Oncology Center, Limassol, Cyprus
}

\begin{abstract}
Background/Aim: Early-stage gastric cancer has a high risk of recurrence, despite trimodality therapy with surgery, chemotherapy and radiation. To improve patient selection for adjuvant chemoradiotherapy, we evaluated the prognostic significance of immunohistochemical and genetic biomarkers in patients with resected gastric adenocarcinoma. Patients and Methods: Tumors from 119 patients were subjected to immunohistochemistry for 12 protein biomarkers, as well as next-generation sequencing. Clinical and biomarker data were available for 91 patients. Results: EBV-
\end{abstract}

This article is freely accessible online.

*These Authors contributed equally to this study.

Correspondence to: E. Pectasides, Department of Medical Oncology, Dana-Farber Cancer Institute, 450 Brookline Ave, Boston, MA 02215, U.S.A. E-mail: eirini_pectasides@ dfci.harvard.edu; hecogoff@otenet.gr

Key Words: Biomarkers, gastric cancer, chemoradiotherapy. positive tumors and tumors with mutations had higher intratumoral CD8 tumor-infiltrating lymphocyte density ( $p=0.009$ and $p=0.017$, respectively). PIK3CA mutations were correlated with VEGFA overexpression ( $p=0.042)$, while KRAS mutations and HER2 expression were mutually exclusive ( $p=0.036)$. PTEN expression univariately confirmed longer overall survival $(H R=0.27 ; p=0.046)$, while there was a trend between the presence of KRAS mutations and inferior disease-free and overall survival. Conclusion: PTEN protein expression and KRAS mutations may predict disease outcome in early-stage gastric cancer. These results need to be further validated in larger cohorts.

Gastric cancer is the fifth most common cancer and the third leading cause of cancer-related mortality worldwide (1). Patients with stage I disease treated with gastrectomy have a 5 -year survival rate of approximately $65 \%$, whereas patients with more advanced disease have poorer outcomes with a 5year survival rate of $30 \%(2,3)$. Complete surgical resection is required to cure gastric cancer (4). However, given the high recurrence rate after surgery, additional therapeutic approaches have been explored. These therapeutic strategies include 
adjuvant concurrent chemotherapy and radiation, perioperative chemotherapy and adjuvant chemotherapy (5-9). Several clinical trials have clearly demonstrated the benefit of these adjunctive approaches compared to surgery alone. According to the National Comprehensive Cancer Network and the European Society for Medical Oncology guidelines, for patients with $\geq$ stage IB gastric cancer who have undergone potentially curative surgical resection, postoperative 5fluorouracil-based chemoradiotherapy is recommended. Despite the proven survival benefit of this approach over surgery alone (5), approximately half of the patients will still relapse and die of their cancer.

Currently, there are no established prognostic or predictive biomarkers for patients with gastric adenocarcinoma who receive adjuvant chemoradiotherapy after potentially curative surgical resection (10). The aim of our current study was to evaluate the prognostic significance of a host of genetic and protein biomarkers in an effort to improve patient selection for adjuvant chemoradiotherapy.

\section{Patients and Methods}

Patient cohort. We performed a retrospective analysis in patients with histologically confirmed primary gastric adenocarcinoma treated at cancer centers affiliated with the Hellenic Cooperative Oncology Group (HeCOG). This translational study was approved by the Bioethics Committee of "Attikon" Hospital, Athens, Greece (8/24-09-09). All patients included in the study provided their written informed consent for the use of their biological material for future research. A total of 119 patients who underwent gastrectomy, adjuvant chemotherapy and radiation therapy for gastric cancer from 2005 to 2013 were included in the study. Of the 119 evaluable patients, 26 did not have complete clinical data, including treatment information and follow-up, and were excluded from further analysis.

Tumor blocks from the 93 patients with complete clinical data were retrieved from the HeCOG tumor repository. Upon histological review, tumors were transferred to tissue microarrays (TMA, $2 \times 1.5 \mathrm{~mm}$ cores per tumor) that were constructed with a manual arrayer (Model I, Beecher Instruments, San Prairie, WI, USA), as previously described $(11,12)$. Upon review of hematoxylin-eosin stained sections from the TMA blocks, 2 tumors had insufficient tissue for biomarker analysis. The REMARK diagram for the study is shown in Figure 1.

Immunohistochemistry. Immunohistochemical staining was performed according to standard protocols on serial $2.5-\mu \mathrm{m}$ thick sections from the TMA blocks. To assure optimal reactivity, immunostaining was applied 7-10 days after sectioning at the Laboratory of Molecular Oncology of the Hellenic Foundation for Cancer Research, Aristotle University of Thessaloniki School of Medicine. The staining procedures for EGFR, HER2, IGF1R, PTEN, pAKT ${ }^{308}$, MTOR, VEGFA, MLH1, MSH2, MSH6, PMS2 are shown in Table I. Tumors were also evaluated for Epstein-Barr virus (EBV) status using Epstein-Barr encoding region (EBER) in situ hybridization (ISH), as previously described (13).

Interpretation of IHC results. The evaluation of all IHC staining was performed by two experienced pathologists, blinded to the patients'
Patients with histologically confirmed primary gastric adenocarcinoma treated with adjuvant chemotherapy: $n=119$

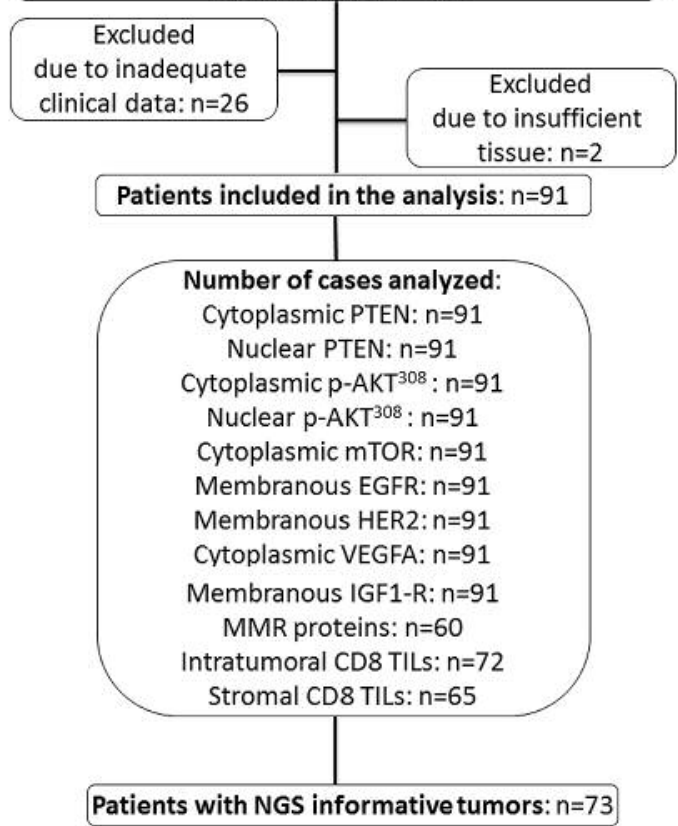

Figure 1. REMARK diagram detailing study cohort. PTEN: Phosphatase and tensin homolog; mTOR: mammalian target of rapamycin; EGFR: epidermal growth factor receptor; HER2: human epidermal growth factor receptor 2; VEGFA: vascular endothelial growth factor A; IGF1$R$ : insulin-like growth factor 1 receptor; MMR: mismatch repair; TILs: tumor-infiltrating lymphocytes; NGS: next-generation sequencing.

clinical characteristics and survival data. For each tumor core, the intensity of staining $(0=$ no staining, $1=$ weakly positive, $2=$ moderately positive, $3=$ strongly positive), the percentage of tumor cells staining positive and the localization of the stain (nuclear, cytoplasmic or membranous) were assessed. Based on these results, protein expression of all markers was summarized using the H-score (or "histo" score), a semiquantitative approach that scores samples based on the percentage of cells at each staining intensity level, with the final score ranging from 0 to 300 , as previously described (14). If one of the tissue cores was lost or damaged the overall score was determined from the remaining one. Cut-offs for protein markers were selected based on previously published studies (15-21). Evaluation of CD8 as intratumoral and stromal infiltrates was performed as previously described $(22,23)$.

Next-generation sequencing (NGS). We used a custom Ampliseq panel targeting coding regions in genes previously reported (24) as frequently mutated in gastric cancer. The interrogated genes (number of amplicons in parentheses) were: APC (4), AURKA (1), BRCAl (9), CDH1 (5), CTNNBB1 (4), FAT4 (10), FGFRl (1), FGFR2 (2), FGFR3 (1), FGFR4 (3), KRAS (2), MLH1 (1), PIK3CA (5), PTCH1 (1), SMAD4 (2), TP53 (8). FFPE DNA was extracted from TMA cores with $>30 \%$ tumor cell content; samples were assessed for quality and processed for semiconductor sequencing as previously described (25). Variants were called with Variant Caller, 
Table I. Staining procedures for EGFR, HER2, IGF1R, PTEN, pAKT308, MTOR, VEGFA, MLH1, MSH2, MSH6, PMS2.

\begin{tabular}{|c|c|c|c|}
\hline IHC stains & Ab info & Manufacturer & Staining protocol \\
\hline PTEN & $\begin{array}{l}\text { Clone } 6 \mathrm{H} 2.1 \text {, code } \mathrm{M} 3627 \text {, } \\
\text { mouse monoclonal }\end{array}$ & DAKO, Glostrup, DK & 20'ER2, 1:300-1h, Bond polymers \\
\hline p-mTOR (Ser 2448) & $\begin{array}{l}\text { Clone } 49 \mathrm{~F} 9 \text {, code } 2976, \\
\text { rabbit monoclonal }\end{array}$ & $\begin{array}{l}\text { Cell Signaling Technology, } \\
\text { Inc, Danvers, MA }\end{array}$ & 20'ER1, 1:30-20', Bond polymers \\
\hline EGFR & $\begin{array}{l}\text { Clone } 31 \mathrm{G} 7 \text {, code } 28-005 \text {, } \\
\text { mouse monoclonal }\end{array}$ & Invitrogen Corporation, Camarillo, CA & enz2-8', 1:50-20', Bond polymers \\
\hline HER2 (c-erbB-2) & Code A 0485 & DAKO, Glostrup, DK & 20'ER1, 1:500-30', Bond polymers \\
\hline VEFG A & Clone VG1, code M7273 & DAKO, Glostrup, DK & 20'ER2, 1:75-1h, Bond polymer \\
\hline MSH-6 & Clone EP49, M3646 & DAKO, Glostrup, DK & 20'ER2, 1:70-30', Bond polymers \\
\hline MSH-2 & Clone 25D12, Code NCL-MSH2 & $\begin{array}{l}\text { Novocastra, Leica Biosystems, Newcastle, } \\
\text { Upon Tyne, UKs }\end{array}$ & 20'ER1, 1:40-30', Bond polymer \\
\hline MLH 1 & Clone ES05 & MONOSAN & 20'ER1, 1:70-20', Bond polymers \\
\hline PMS-2 & Clone M0R4G & $\begin{array}{l}\text { Novocastra, Leica Biosystems, Newcastle, } \\
\text { Upon Tyne, UK }\end{array}$ & 20'ER2, 1:50-20', Bond polymers \\
\hline IGF-IRa & $\begin{array}{l}\text { Clone } 24-31 \text {, code MS-641-P, } \\
\text { mouse monoclonal }\end{array}$ & Thermo Scientific & enz2-8', 1:50-1h, Bond polymers \\
\hline pAKT308 & Code sc-16646-R & Santa Cruz, Santa Cruz, CA & 20'ER1, 1:1000 O/N, Bond polymer \\
\hline CD8 & Clone C8-144B, code M7103 & DAKO, Glostrup, DK & $\begin{array}{l}\text { 20'ER2, 1:80-20', Bond polymer } \\
\text { Enz2=proteinase } \\
\text { ER1=citric acid } \\
\text { ER2=EDTA }\end{array}$ \\
\hline
\end{tabular}

extensively filtered for quality, initially annotated with Ion Reporter (Thermo-Fisher) and further with COSMIC based on provided fathmm scores for pathogenicity. We processed amino acid and splice site changing variants as mutations for minor allele frequencies $<0.01 \%$ (NCBI dbSNP, 5000Exomes, ExAC) that were read at least $\times 40$ for positions read at least $\times 100$.

With the applied panel of 59 informative amplicons, we considered $>7,500$ mapped reads and $>125$ mean depth for sample eligibility. The 73 informative tumors had average and median mean depth of 975.4 and 645 , respectively; an average and median number of 12.4 and 11 variants, respectively (range=2-72); and, an average of 1.6 mutations (range $=0-28$ ).

Statistical analysis. The cut-offs previously described in the "Patients and Methods" section were used to categorize tumors into positive and negative protein-expressing. In addition, the respective distributions of the calculated $\mathrm{H}$-score of the immunohistochemical markers was plotted (Figure 2) to detect potential cut-offs by examining the quartiles of the distributions. Selected cut-offs for mTOR, p-AKT ${ }^{308}$ and intratumoral and stromal CD8 TILs were the $50^{\text {th }}$ percentiles (median value) of the respective distributions, while the $25^{\text {th }}$ percentile was selected for IGF1-R.

The Chi-square or Fisher's exact (where appropriate) test was used for group comparisons of categorical data, while the Wilcoxon rank-sum test was performed to detect differences between categorical and continuous variables.

Disease-free survival (DFS) was defined as the time (in months) from surgery to first documented progression, death from gastric cancer or last contact (whichever occurred first). Overall survival (OS) was defined as the time from surgery to death from gastric cancer, with alive patients being censored at the date of last contact.
Survival curves were estimated using the Kaplan-Meier product limit method and compared across groups with the log-rank test.

The prognostic significance of the examined immunohistochemical biomarkers and genes was evaluated by hazard ratios (HRs) estimated with univariate and multivariate Cox proportional hazard regression models with Firth's correction (where appropriate). All parameters were tested for proportionality using time-dependent covariates. In multivariate analysis, each of the markers or genes that showed significance in the univariate analyses was adjusted for age at diagnosis, histological grade (reference category: grade I-II), number of positive nodes (reference category: 0-3) and performance status (reference category: 0 ).

Associations of gene mutational status with immunohistochemical markers, clinicopathological characteristics and outcome were performed only for TP53, PIK3CA and KRAS, as the mutation frequency of the other genes was too low to allow for meaningful interpretation.

All analyses were performed in the entire cohort. All tests were two-sided at an alpha 5\% level of significance. Analyses were conducted using the SAS software (version 9.3, SAS Institute Inc., Cary, NC, USA).

\section{Results}

Patient characteristics. As shown in the REMARK diagram (Figure 1), among 119 patients initially included in the analysis, 91 had complete clinical and biomarker data. Basic clinical and pathological characteristics are presented in Table II. The median age at diagnosis was 64 years and the majority of patients were males $(73.6 \%)$ with intestinal type 

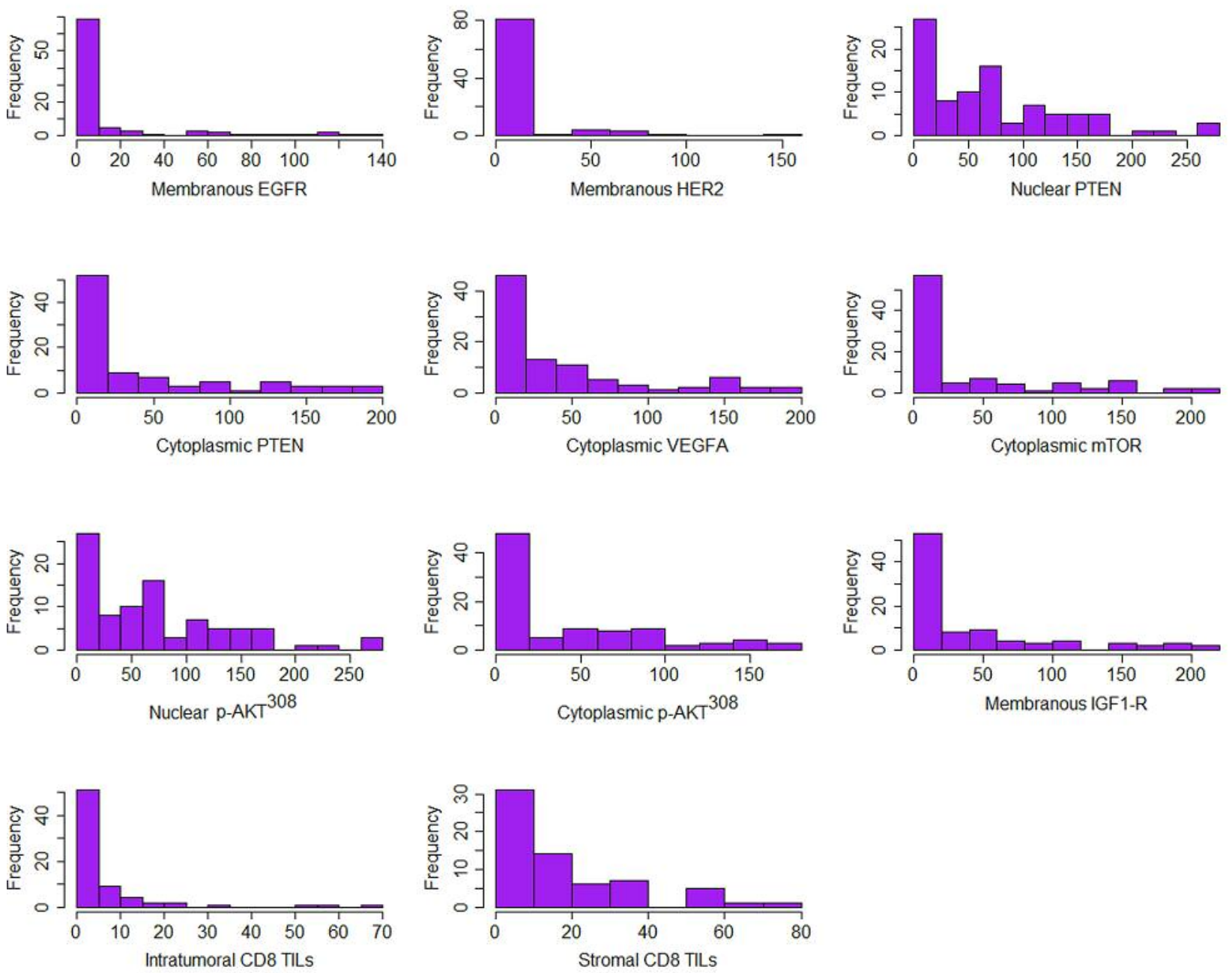

Figure 2. Distribution of calculated H-scores of immunohistochemical markers across the cohort. Histograms represent the distribution of expression of membranous EGFR, membranous HER2, nuclear PTEN, cytoplasmic PTEN, cytoplasmic VEGFA, cytoplasmic mTOR, nuclear p-AKT308, cytoplasmic p-AKT 308 , membranous IGF1-R, intratumoral CD8 TILs and stromal CD8 TILs.

tumors $(56 \%)$, of T3 stage $(60.4 \%)$ involving the distal stomach $(43.7 \%)$. All patients received adjuvant chemotherapy and $93.3 \%$ of patients received adjuvant radiotherapy. In our cohort, 4 patients $(4.4 \%)$ had confirmed EBV-positive disease, based on EBER ISH.

Frequency distribution of immunohistochemical markers and clinically relevant mutations in the cohort. Among 91 patients, $9(9.9 \%)$ had HER2-positive tumors, while 14 (15.4\%) had EGFR-positive disease. MMR status was informative for 60 patients $(65.9 \%)$ and 11 of them (18.3\%) had MMR deficient (dMMR) tumors.

Data on intratumoral and stromal CD8 TILs were available for $72(79.1 \%)$ and $65(71.4 \%)$ patients, respectively. More than half of the patients with available information had tumors with high intratumoral CD8 TILs (40 patients; $55.6 \%)$ and 34 patients (52.3\%) had high stromal CD8 TILs expression, while 24 patients (36.9\%) had high expression of both intratumoral and stromal CD8 TILs. The frequency distribution of all examined immunohistochemical markers is presented in Table III.

Regarding mutations in clinically relevant genes, NGS revealed 115 mutations (median: 1 ; range $=0-28$ ) distributed in 44 of the 73 informative tumors $(60.3 \%)$. The most frequently mutated genes were TP53 in 19 tumors (43.2\% of mutated; $26.0 \%$ of all informative tumors), PIK3CA in 9 tumors $(20.5 \%$ of mutated; $12.3 \%$ of all informative tumors) and KRAS in 24 tumors $(54.5 \%$ of mutated; $32.9 \%$ of all informative tumors) (Figure 3). Less frequent mutations occurred in the following genes: CDH1 (11.0\%), FAT4 (6.8\%), BRCA1 (4.1\%), CTNNB1 (2.7\%), AURKA (2.7\%), FGFR4 (2.7\%), SMAD4 (1.4\%), APC (1.4\%) and FGFR2 (1.4\%). 
Table II. Basic patient and tumor characteristics.

\begin{tabular}{|c|c|}
\hline & $\begin{array}{c}\text { Total } \\
(\mathrm{N}=91)\end{array}$ \\
\hline Age & $64.0(37.0,78.0)$ \\
\hline$\leq 64$ & $46(50.5)$ \\
\hline$>64$ & $45(49.5)$ \\
\hline \multicolumn{2}{|l|}{ Gender } \\
\hline \multicolumn{2}{|l|}{ Male } \\
\hline Female & $67(73.6)$ \\
\hline \multicolumn{2}{|l|}{$24(26.4)$} \\
\hline \multicolumn{2}{|l|}{$\mathrm{N}$ of positive nodes } \\
\hline $0-3$ & $47(51.6)$ \\
\hline$\geq 4$ & $44(48.4)$ \\
\hline \multicolumn{2}{|l|}{ Histological grade* } \\
\hline I-II & $38(42.7)$ \\
\hline III & $51(57.3)$ \\
\hline \multicolumn{2}{|l|}{ Histology } \\
\hline Adenosquamous & $1(1.1)$ \\
\hline Diffuse & $25(27.5)$ \\
\hline Intestinal & $51(56.0)$ \\
\hline Mixed & $10(11.0)$ \\
\hline Mucinous & $4(4.4)$ \\
\hline \multicolumn{2}{|l|}{ T stage } \\
\hline 1 & $2(2.2)$ \\
\hline 2 & $21(23.1)$ \\
\hline 3 & $55(60.4)$ \\
\hline 4 & $13(14.3)$ \\
\hline \multicolumn{2}{|l|}{ Primary site* } \\
\hline Proximal & $24(27.6)$ \\
\hline Distal & $38(43.7)$ \\
\hline Neither & $25(28.7)$ \\
\hline \multicolumn{2}{|c|}{ Performance status* } \\
\hline 0 & $77(86.5)$ \\
\hline $1-2$ & $12(13.5)$ \\
\hline \multicolumn{2}{|c|}{ Adjuvant radiotherapy* } \\
\hline No & $6(6.7)$ \\
\hline Yes** & $84(93.3)$ \\
\hline \multicolumn{2}{|c|}{ Type of lymphadenectomy } \\
\hline D0 & $2(2.2)$ \\
\hline D1 & $66(72.5)$ \\
\hline $\mathrm{D} 2$ & $23(25.3)$ \\
\hline \multicolumn{2}{|c|}{ Helicobacter pylori infection* } \\
\hline No & $79(91.9)$ \\
\hline Yes & $7(8.1)$ \\
\hline \multicolumn{2}{|l|}{ EBV status } \\
\hline Negative & $87(95.6)$ \\
\hline Positive & $4(4.4)$ \\
\hline \multicolumn{2}{|l|}{ Smoking* } \\
\hline No & $40(47.6)$ \\
\hline Yes & $44(52.4)$ \\
\hline \multicolumn{2}{|l|}{ Alcohol abuse* } \\
\hline No & $71(85.5)$ \\
\hline Yes & $12(14.5)$ \\
\hline
\end{tabular}

N: Number. *Data not available for all subjects Missing values: Histological grade $=2$, Primary site $=4$, Performance status $=2$, Adjuvant radiotherapy $=1$, Helicobacter pylori infection $=5$, Smoking $=7$, Alcohol abuse $=8$. **37 patients underwent radiotherapy with concurrent adjuvant chemotherapy. Values are presented as Median (min, max) or $\mathrm{N}$ (column \%).
Table III. Frequency distribution of the immunohistochemical markers of interest.

\begin{tabular}{|c|c|}
\hline & $\begin{array}{c}\text { Total } \\
(\mathrm{N}=91)\end{array}$ \\
\hline CD8 intratumoral TILs* & $5.0(0.00,70.0)$ \\
\hline High & $40(55.6)$ \\
\hline Low & $32(44.4)$ \\
\hline CD8 stromal TILs* & $15.0(1.00,80.0)$ \\
\hline High & $34(52.3)$ \\
\hline Low & $31(47.7)$ \\
\hline \multicolumn{2}{|l|}{ Membranous EGFR } \\
\hline Negative & $77(84.6)$ \\
\hline Positive & $14(15.4)$ \\
\hline \multicolumn{2}{|l|}{ Membranous HER2 } \\
\hline Negative & $82(90.1)$ \\
\hline Positive & $9(9.9)$ \\
\hline \multicolumn{2}{|l|}{ Nuclear PTEN } \\
\hline Negative & $78(85.7)$ \\
\hline Positive & $13(14.3)$ \\
\hline \multicolumn{2}{|l|}{ Cytoplasmic PTEN } \\
\hline Negative & $41(45.1)$ \\
\hline Positive & $50(54.9)$ \\
\hline \multicolumn{2}{|l|}{ Cytoplasmic VEGFA } \\
\hline Negative & $42(46.2)$ \\
\hline Positive & $49(53.8)$ \\
\hline \multicolumn{2}{|l|}{ Cytoplasmic mTOR } \\
\hline Negative & $46(50.5)$ \\
\hline Positive & $45(49.5)$ \\
\hline \multicolumn{2}{|l|}{ Nuclear p-AKT308 } \\
\hline Negative & $46(50.5)$ \\
\hline Positive & $45(49.5)$ \\
\hline \multicolumn{2}{|l|}{ Cytoplasmic p-AKT308 } \\
\hline Negative & $48(52.7)$ \\
\hline Positive & $43(47.3)$ \\
\hline \multicolumn{2}{|l|}{ Membranous IGF1-R } \\
\hline Negative & $31(34.1)$ \\
\hline Positive & $60(65.9)$ \\
\hline \multicolumn{2}{|l|}{ MMR status* } \\
\hline Deficient & $11(18.3)$ \\
\hline Proficient & $49(81.7)$ \\
\hline
\end{tabular}

*Data not available for all subjects. Missing values: CD8 intratumoral TILs=19, CD8 stromal TILs=26, MMR=31. Values are presented as Median (min, max) or N (column \%).

Association of immunohistochemical markers with TP53, PIK3CA and KRAS mutations. The associations between the examined IHC markers and the mutational status of the three top mutated genes (KRAS, TP53, PIK3CA) are presented in Table IV. Tumors without TP53 mutations had more frequent cytoplasmic VEGFA protein expression (chi-square $p=0.034$, Figure 4A). Notably, all 24 tumors carrying KRAS mutation were HER2-negative by IHC (Fisher's $p=0.036$, Figure 4B), while 8 of the 9 tumors with PIK3CA mutation were also positive for VEGFA protein expression (Fisher's $p=0.042$, Figure 4C). Tumors with mutations had more frequently negative nuclear PTEN protein expression (Fisher's $p=0.035$, 


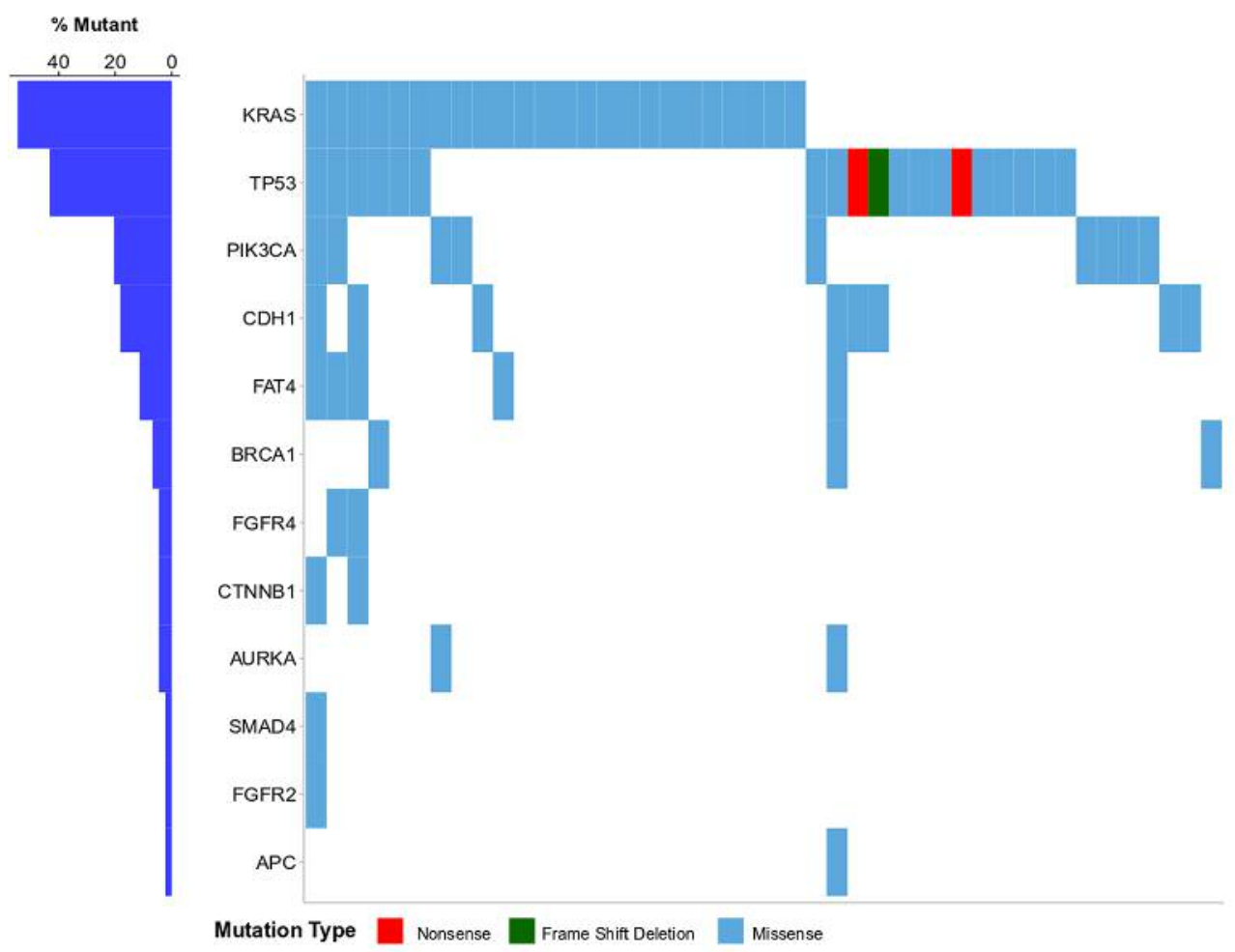

Figure 3. Map of pathogenic mutations in 73 gastric cancers. Using a targeted panel of 16 frequently mutated genes, we detected mutations in 44 of 73 tumors (60.3\%). The most frequently mutated genes were TP53 in 19 tumors (43.2\% of mutated; $26.0 \%$ of all informative tumors), PIK3CA in 9 tumors (20.5\% of mutated; $12.3 \%$ of all informative tumors) and KRAS in 24 tumors (54.5\% of mutated; $32.9 \%$ of all informative tumors).

Figure 4D) and higher density of intratumoral CD8 TILs (Wilcoxon rank-sum $p=0.017$, Figure $4 \mathrm{E}$ ) as compared to those without. No further significant associations were observed.

Association of immunohistochemical markers with clinicopathologic parameters. Patients with tumors of positive HER2 and VEGFA protein expression were of older age at the time of diagnosis (median age: 73 vs. 63.5, Wilcoxon ranksum $p=0.011$ and median age: 68 vs. 62.5, $p=0.011$, respectively). In addition, tumors with negative VEGFA protein expression were more frequently of higher grade (III) compared to those with positive expression of VEGFA (70\% vs. $46.9 \%$, chi-square $p=0.029)$. Positive cytoplasmic expression of PTEN was associated with advanced nodal stage $(p=0.042)$. In addition, EBV-positive tumors were characterized by higher intratumoral CD8 TIL density as compared to EBV-negative (median $60 \mathrm{vs}$. 5, Wilcoxon ranksum $p=0.009)$, while there was no association between stromal CD8 TILs and EBV status $(p=0.54)$.

The differences in the distribution of the number of mutations per tumor based on the expression of the examined immunohistochemical markers were also examined. The number of mutations was higher in tumors of negative HER2 protein expression compared to tumors of positive HER2 expression (median 1 vs. 0, Wilcoxon rank-sum $p=0.030$ ). The number of mutations per tumor did not differ between tumors with high and low intratumoral or stromal CD8 TILs ( $p=0.11$ and $p=0.46$, respectively) but the presence of any number of mutations was associated with high intratumoral CD8 infiltrates (Table IV).

Association of TP53, PIK3CA and KRAS mutations with clinicopathologic characteristics. PIK3CA-mutant tumors were more likely to be well or moderately differentiated (grade I or II) (Fisher's $p=0.025)$, distal $(p=0.026)$ and more frequently observed in non-smokers $(p=0.031)$ compared to PIK3CA wild-type tumors, while no further significant associations were observed between the mutational status of TP53, PIK3CA or KRAS and the selected clinicopathological parameters. The presence of mutation (s) was more frequent in male patients $(p=0.034)$.

Prognostic value of immunohistochemical biomarkers and mutational status. At a median follow-up of 98.1 months (95\% CI=87.7-109.3), a total of 49 events of progression or death (DFS events) had been reported. Fifty-four patients 
Table IV. Associations of the examined immunohistochemical markers with TP53, KRAS, PIK3CA and the presence of mutations.

\begin{tabular}{|c|c|c|c|c|c|c|c|c|c|c|c|c|}
\hline & \multicolumn{3}{|c|}{ TP53 mutations } & \multicolumn{3}{|c|}{ KRAS mutations } & \multicolumn{3}{|c|}{ PIK3CA mutations } & \multicolumn{3}{|c|}{ Presence of mutations } \\
\hline & No & Yes & $p$-Value & No & Yes & $p$-Value & No & Yes & $p$-Value & No & Yes & $p$-Value \\
\hline CD8 intratumoral TILs & $\begin{array}{c}5.0 \\
(0.00,70.0)\end{array}$ & $\begin{array}{c}5.0 \\
(0.00,60.0)\end{array}$ & 0.21 & $\begin{array}{c}5.0 \\
(0.00,55.0)\end{array}$ & $\begin{array}{c}6.0 \\
(0.00,70.0)\end{array}$ & 0.10 & $\begin{array}{c}5.0 \\
(0.00,70.0)\end{array}$ & $\begin{array}{c}5.5 \\
(0.00,55.0)\end{array}$ & 0.45 & $\begin{array}{c}1.0 \\
(0.00,25.0)\end{array}$ & $\begin{array}{c}5.0 \\
(0.00,70.0)\end{array}$ & 0.017 \\
\hline CD8 stromal TILs & $\begin{array}{c}10.0 \\
(1.00,70.0)\end{array}$ & $\begin{array}{c}20.0 \\
(5.0,80.0)\end{array}$ & 0.14 & $\begin{array}{c}15.0 \\
(1.00,70.0)\end{array}$ & $\begin{array}{c}10.0 \\
(1.00,80.0)\end{array}$ & 0.38 & $\begin{array}{c}12.5 \\
(1.00,80.0)\end{array}$ & $\begin{array}{c}5.0 \\
(1.00,60.0)\end{array}$ & 0.54 & $\begin{array}{c}10.0 \\
(1.00,70.0)\end{array}$ & $\begin{array}{c}15.0 \\
(1.00,80.0)\end{array}$ & 0.74 \\
\hline Membranous EGFR & & & 0.93 & & & 0.53 & & & 0.65 & & & 0.88 \\
\hline Negative & $45(83.3)$ & $16(84.2)$ & & $40(81.6)$ & $21(87.5)$ & & $53(82.8)$ & $8(88.9)$ & & $24(82.8)$ & $37(84.1)$ & \\
\hline Positive & $9(16.7)$ & $3(15.8)$ & & $9(18.4)$ & $3(12.5)$ & & $11(17.2)$ & $1(11.1)$ & & $5(17.2)$ & $7(15.9)$ & \\
\hline Membranous HER2 & & & 0.36 & & & 0.036 & & & 0.26 & & & 0.052 \\
\hline Negative & $47(87.0)$ & $18(94.7)$ & & $41(83.7)$ & $24(100.0)$ & & $56(87.5)$ & $9(100.0)$ & & $23(79.3)$ & $42(95.5)$ & \\
\hline Positive & $7(13.0)$ & $1(5.3)$ & & $8(16.3)$ & $0(0.0)$ & & $8(12.5)$ & $0(0.0)$ & & $6(20.7)$ & $2(4.5)$ & \\
\hline Nuclear PTEN & & & 0.64 & & & 0.097 & & & 0.20 & & & 0.035 \\
\hline Negative & $46(85.2)$ & $17(89.5)$ & & $40(81.6)$ & $23(95.8)$ & & $54(84.4)$ & $9(100.0)$ & & $22(75.9)$ & $41(93.2)$ & \\
\hline Positive & $8(14.8)$ & $2(10.5)$ & & $9(18.4)$ & $1(4.2)$ & & $10(15.6)$ & $0(0.0)$ & & $7(24.1)$ & $3(6.8)$ & \\
\hline Cytoplasmic PTEN & & & 0.97 & & & 0.68 & & & 0.40 & & & 0.88 \\
\hline Negative & $23(42.6)$ & $8(42.1)$ & & $20(40.8)$ & $11(45.8)$ & & $26(40.6)$ & $5(55.6)$ & & $12(41.4)$ & $19(43.2)$ & \\
\hline Positive & $31(57.4)$ & $11(57.9)$ & & $29(59.2)$ & $13(54.2)$ & & $38(59.4)$ & $4(44.4)$ & & $17(58.6)$ & $25(56.8)$ & \\
\hline Cytoplasmic VEGFA & & & 0.034 & & & 0.55 & & & 0.042 & & & 0.74 \\
\hline Negative & $19(35.2)$ & $12(63.2)$ & & $22(44.9)$ & $9(37.5)$ & & $30(46.9)$ & $1(11.1)$ & & $13(44.8)$ & $18(40.9)$ & \\
\hline Positive & $35(64.8)$ & $7(36.8)$ & & $27(55.1)$ & $15(62.5)$ & & $34(53.1)$ & $8(88.9)$ & & $16(55.2)$ & $26(59.1)$ & \\
\hline Cytoplasmic mTOR & & & 0.32 & & & 0.56 & & & 0.99 & & & 0.094 \\
\hline Negative & $27(50.0)$ & $7(36.8)$ & & $24(49.0)$ & $10(41.7)$ & & $30(46.9)$ & $4(44.4)$ & & $17(58.6)$ & $17(38.6)$ & \\
\hline Positive & $27(50.0)$ & $12(63.2)$ & & $25(51.0)$ & $14(58.3)$ & & $34(53.1)$ & $5(55.6)$ & & $12(41.4)$ & $27(61.4)$ & \\
\hline Nuclear p-AKT 308 & & & 0.55 & & & 0.21 & & & 0.48 & & & 0.14 \\
\hline Negative & $27(50.0)$ & $11(57.9)$ & & $23(46.9)$ & $15(62.5)$ & & $32(50.0)$ & $6(66.7)$ & & $12(41.4)$ & $26(59.1)$ & \\
\hline Positive & $27(50.0)$ & $8(42.1)$ & & $26(53.1)$ & $9(37.5)$ & & $32(50.0)$ & $3(33.3)$ & & $17(58.6)$ & $18(40.9)$ & \\
\hline Cytoplasmic p-AKT ${ }^{308}$ & & & 0.21 & & & 0.79 & & & 0.16 & & & 0.27 \\
\hline Negative & $28(51.9)$ & $13(68.4)$ & & $27(55.1)$ & $14(58.3)$ & & $34(53.1)$ & $7(77.8)$ & & $14(48.3)$ & $27(61.4)$ & \\
\hline Positive & $26(48.1)$ & $6(31.6)$ & & $22(44.9)$ & $10(41.7)$ & & $30(46.9)$ & $2(22.2)$ & & $15(51.7)$ & $17(38.6)$ & \\
\hline Membranous IGF1-R & & & 0.37 & & & 0.25 & & & 0.21 & & & 0.86 \\
\hline Negative & $14(25.9)$ & $7(36.8)$ & & $12(24.5)$ & $9(37.5)$ & & $20(31.3)$ & $1(11.1)$ & & $8(27.6)$ & $13(29.5)$ & \\
\hline Positive & $40(74.1)$ & $12(63.2)$ & & $37(75.5)$ & $15(62.5)$ & & $44(68.8)$ & $8(88.9)$ & & $21(72.4)$ & $31(70.5)$ & \\
\hline MMR status & & & 0.20 & & & 0.20 & & & 0.34 & & & 0.39 \\
\hline Deficient & $8(22.9)$ & $1(7.1)$ & & $8(22.9)$ & $1(7.1)$ & & $8(17.0)$ & $1(50.0)$ & & $5(23.8)$ & $4(14.3)$ & \\
\hline Proficient & $27(77.1)$ & $13(92.9)$ & & $27(77.1)$ & $13(92.9)$ & & $39(83.0)$ & $1(50.0)$ & & $16(76.2)$ & $24(85.7)$ & \\
\hline CD8 intratumoral TILs & & & 0.50 & & & 0.45 & & & 0.45 & & & 0.048 \\
\hline High & $25(56.8)$ & $10(66.7)$ & & $23(56.1)$ & $12(66.7)$ & & $29(56.9)$ & $6(75.0)$ & & $10(43.5)$ & $25(69.4)$ & \\
\hline Low & $19(43.2)$ & $5(33.3)$ & & $18(43.9)$ & $6(33.3)$ & & $22(43.1)$ & $2(25.0)$ & & $13(56.5)$ & $11(30.6)$ & \\
\hline CD8 stromal TILs & & & 0.094 & & & 0.59 & & & 0.99 & & & 0.48 \\
\hline High & $17(42.5)$ & $9(69.2)$ & & $20(51.3)$ & $6(42.9)$ & & $23(50.0)$ & $3(42.9)$ & & $10(43.5)$ & $16(53.3)$ & \\
\hline Low & $23(57.5)$ & $4(30.8)$ & & $19(48.7)$ & $8(57.1)$ & & $23(50.0)$ & $4(57.1)$ & & $13(56.5)$ & $14(46.7)$ & \\
\hline
\end{tabular}

(59.3\%) had died, 42 from their disease. The median DFS and OS was 49.9 months and 91.9 months, respectively.

None of the examined immunohistochemical markers showed prognostic significance with respect to DFS (Table V). Similarly, mutations in TP53 and PIK3CA genes were not found to be prognostic for DFS. In terms of OS, only positive expression of nuclear PTEN was associated with marginally longer survival ( $\mathrm{HR}=0.27$; Wald's $p=0.046$ ) (Figure 5A). It should be noted, however, that there were only 2 events of death among patients with nuclear PTEN expression. The power of this result is, therefore, limited by the small number of patients with events and should be interpreted with caution until further validated in larger cohorts. A trend associated with shorter DFS and OS was observed for KRAS mutations (Figure 5B and 5C, respectively).

Upon multivariate analysis with respect to DFS, adjusting for selected clinicopathological parameters (see Methods Statistical Analysis), mutated KRAS did not show prognostic 
A

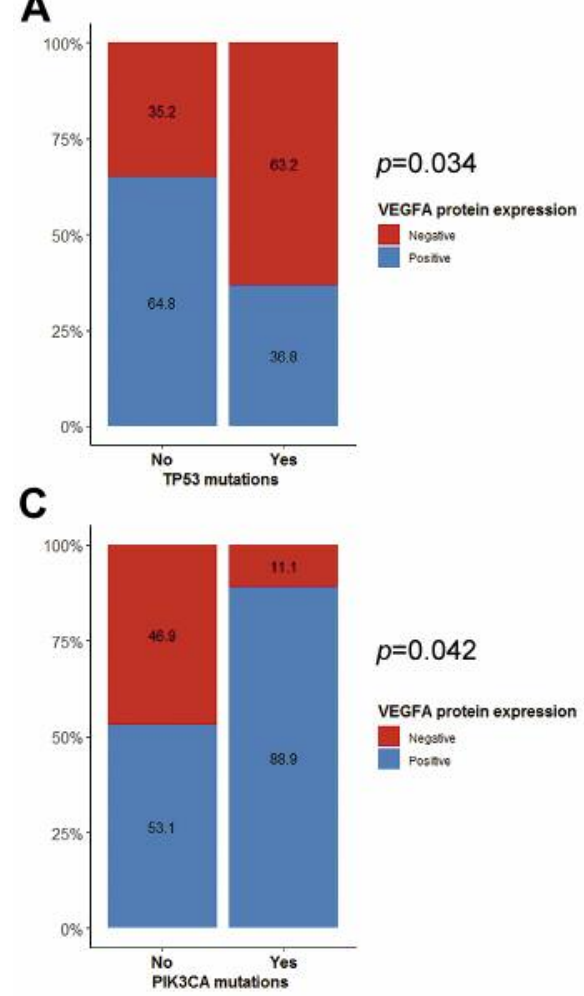

B

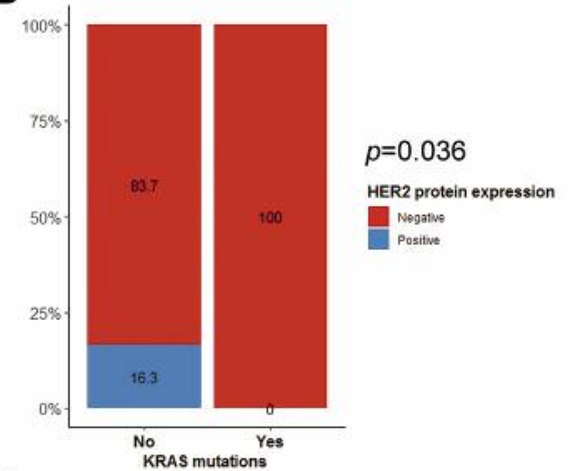

D

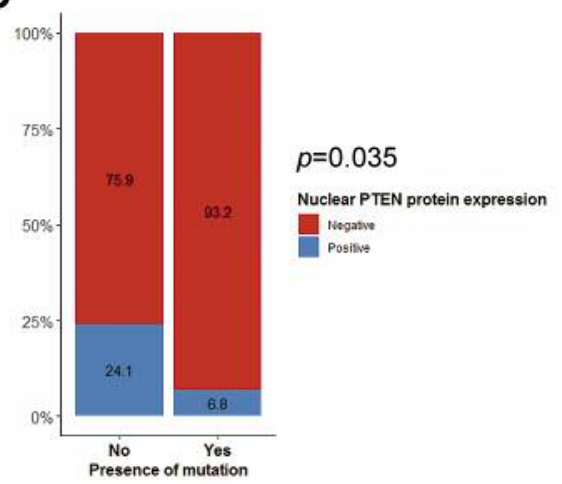

E

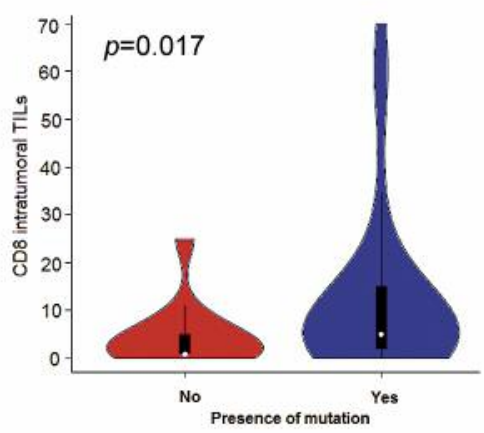

Figure 4. Associations of immunohistochemical markers with TP53, PIK3CA and KRAS mutations. A. Tumors without TP53 mutations had more frequent cytoplasmic VEGFA protein expression (chi-square $p=0.034$ ). B. All 24 tumors harboring KRAS mutation were HER2-negative (Fisher's $p=0.036)$. C. Eight of 9 tumors with PIK3CA mutation were positive for VEGFA protein expression (Fisher's $p=0.042$ ). D. Tumors with mutations had more frequently negative nuclear PTEN protein expression (Fisher's $p=0.035$ ). E. Tumors with mutations had a higher density of intratumoral CD8 TILs (Wilcoxon rank-sum $p=0.017$ ).

significance for DFS (HR=1.60; $p=0.15)$ (Table VI). Regarding OS, both mutated KRAS and positive nuclear PTEN protein expression were not prognostic for OS upon adjustment for clinicopathological parameters.

\section{Discussion}

In the present study, we sought to determine the prognostic significance of genetic and protein biomarkers in patients with potentially curable gastric adenocarcinoma, who underwent surgical resection and adjuvant chemoradiotherapy.

Of the evaluable patients in our cohort, we identified $4.4 \%$ (4/91) of patients with EBV-positive tumors and $18.3 \%$ $(11 / 60)$ of patients with dMMR tumors. Our findings are in line with the frequency of EBV-positivity and microsatellite instability (MSI) in The Cancer Genome Atlas (TCGA) cohort (24). EBV-positive and dMMR or MSI-high gastric cancer has been associated with high intratumoral CD8 TIL density (2628). In our study, we indeed found a significant correlation between EBV-positivity and intratumoral CD8 TILs. Given this marked immune infiltration, metastatic EBV-positive gastric cancer has exhibited sensitivity to pembrolizumab in a single-arm phase II clinical trial (29). While this clinical activity needs to be confirmed in larger clinical trials, it also begs the question whether immune checkpoint inhibition is efficacious in the adjuvant treatment of EBV-positive gastric cancer. In contrast to previous reports, there was no statistically significant association between MMR deficiency and CD8 lymphocyte infiltration in our cohort. As shown by Cho and colleagues (26), CD8 TIL infiltration is more pronounced in EBV-positive tumors, compared to MSI-high tumors. It is, therefore, likely that in our study, we did not have sufficient statistical power to detect a significant association between MMR deficiency and CD8 TIL density due to our small sample size. Interestingly, we did not find an association between MMR status and survival, as has been shown in early-stage colorectal cancer (30). A recent analysis of MSI/MMR status in the MAGIC trial cohort showed that patients with MSI-high/dMMR tumors who were treated with surgery alone without perioperative chemotherapy had superior survival compared to patients with MSI-high/dMMR 
Table V. Results of Cox univariate regression for immunohistochemical markers and TP53, KRAS and PIK3CA with respect to DFS and OS.

\begin{tabular}{|c|c|c|c|c|c|c|c|c|c|c|}
\hline \multirow[b]{2}{*}{ Parameter } & \multirow[b]{2}{*}{ Categories } & \multirow[b]{2}{*}{$\begin{array}{l}\text { No. of } \\
\text { patients }\end{array}$} & \multirow[b]{2}{*}{$\begin{array}{l}\text { No. of } \\
\text { events }\end{array}$} & \multicolumn{3}{|c|}{$D F S$} & \multirow[b]{2}{*}{$\begin{array}{l}\text { No. of } \\
\text { events }\end{array}$} & \multicolumn{3}{|c|}{$O S$} \\
\hline & & & & HR & $95 \% \mathrm{CI}$ & $p$-Value & & HR & $95 \% \mathrm{CI}$ & $p$-Value \\
\hline Cytoplasmic PTEN & Positive $v s$. Negative & 50 vs. 41 & $25 v s .24$ & 0.73 & $0.41-1.28$ & 0.27 & 22 vs. 20 & 0.86 & $0.47-1.58$ & 0.63 \\
\hline Nuclear PTEN & Positive $v s$. Negative & 13 vs. 78 & 4 vs. 45 & 0.44 & $0.17-1.18$ & $0.10 *$ & $2 v s .40$ & 0.27 & $0.07-0.98$ & $0.046^{*}$ \\
\hline Cytoplasmic VEGFA & Positive vs. Negative & 49 vs. 42 & 23 vs. 26 & 0.73 & $0.41-1.27$ & 0.26 & 19 vs. 23 & 0.65 & $0.35-1.19$ & 0.16 \\
\hline Cytoplasmic mTOR & Positive $v s$. Negative & 45 vs. 46 & $21 v s .28$ & 0.69 & $0.39-1.22$ & 0.20 & $20 v s .22$ & 0.87 & $0.48-1.60$ & 0.66 \\
\hline Cytoplasmic $\mathrm{p}-\mathrm{AKT}^{308}$ & Positive $v s$. Negative & 43 vs. 48 & $22 v s .27$ & 0.98 & $0.56-1.71$ & 0.93 & $21 v s .21$ & 1.24 & $0.68-2.27$ & 0.49 \\
\hline Nuclear p-AKT 308 & Positive vs. Negative & 45 vs. 46 & $21 v s .28$ & 0.62 & $0.35-1.10$ & 0.10 & 19 vs. 23 & 0.71 & $0.39-1.30$ & 0.27 \\
\hline Membranous EGFR & Positive vs. Negative & 14 vs. 77 & $8 v s .41$ & 0.95 & $0.45-2.03$ & 0.90 & 8 vs. 34 & 1.22 & $0.57-2.64$ & 0.61 \\
\hline Membranous HER2 & Positive $v s$. Negative & $9 v s .82$ & 3 vs. 46 & 1.13 & $0.38-3.40$ & $0.83^{*}$ & 3 vs. 39 & 1.49 & $0.49-4.51$ & $0.49 *$ \\
\hline Membranous IFG1-R & Positive vs. Negative & $60 v s .31$ & 29 vs. 20 & 0.66 & $0.37-1.17$ & 0.16 & 26 vs. 16 & 0.78 & $0.42-1.45$ & 0.42 \\
\hline MMR status & Proficient $v s$. Deficient & 49 vs. 11 & $28 v s .5$ & 1.45 & $0.57-3.66$ & $0.44 *$ & $26 v s .3$ & 2.18 & $0.70-6.77$ & $0.18 *$ \\
\hline Intratumoral CD8 TILs & Low vs. High & 32 vs. 40 & 20 vs. 21 & 1.44 & $0.78-2.66$ & 0.24 & 18 vs. 17 & 1.38 & $0.71-2.68$ & 0.34 \\
\hline Stromal CD8 TILs & Low $v s$. High & 31 vs. 34 & $20 v s .16$ & 1.68 & $0.87-3.24$ & 0.12 & 17 vs. 14 & 1.43 & $0.70-2.90$ & 0.32 \\
\hline No. of mutations per tumor ${ }^{\wedge}$ & & & & 0.98 & $0.90-1.07$ & 0.63 & & 0.99 & $0.91-1.08$ & 0.83 \\
\hline KRAS mutation & Yes $v s$. No & 24 vs. 49 & $18 v s .23$ & 1.79 & $0.97-3.34$ & 0.064 & 15 vs. 20 & 1.79 & $0.92-3.51$ & 0.089 \\
\hline PIK3CA mutation & Yes vs. No & $9 v s .64$ & 3 vs. 38 & 0.44 & $0.15-1.35$ & $0.15^{*}$ & $2 v s .33$ & 0.40 & $0.11-1.47$ & $0.17 *$ \\
\hline TP53 mutation & Yes vs. No & 19 vs. 54 & $10 v s .31$ & 0.70 & $0.34-1.43$ & 0.33 & 10 vs. 25 & 0.94 & $0.45-1.96$ & 0.87 \\
\hline
\end{tabular}

No.: Number, HR: hazard ratio, CI: confidence interval. *Firth's correction was applied due to rare events. ^ continuous variable.

Table VI. Results of Cox multivariate regression analysis with respect to DFS and OS.

\begin{tabular}{|c|c|c|c|c|c|c|}
\hline Parameter & Categories & No. of patients & No. of events & HR & $95 \% \mathrm{CI}$ & $p$-Value \\
\hline \multicolumn{7}{|l|}{$D F S$} \\
\hline KRAS mutation & Yes $v s$. No & 23 vs. 47 & 17 vs. 23 & 1.60 & $0.84-3.04$ & 0.15 \\
\hline Histological grade & III $v s$. I-II & 39 vs. 31 & 23 vs. 17 & 1.00 & $0.53-1.91$ & 0.99 \\
\hline No. of positive nodes & $\geq 4$ vs. $0-3$ & 32 vs. 38 & 18 vs. 22 & 1.15 & $0.59-2.21$ & 0.69 \\
\hline Performance status & $1-2$ vs. 0 & 9 vs. 61 & 7 vs. 33 & 2.33 & $1.01-5.39$ & 0.048 \\
\hline $\operatorname{Age}^{\wedge}$ & & & & 1.00 & $0.97-1.04$ & 0.97 \\
\hline \multicolumn{7}{|l|}{ OS } \\
\hline KRAS mutation & Yes vs. no & 23 vs. 47 & 14 vs. 20 & 1.41 & $0.70-2.85$ & 0.34 \\
\hline Nuclear PTEN & Positive $v s$. Negative & $8 v s .62$ & $2 v s .32$ & 0.50 & $0.12-1.99$ & $0.32 *$ \\
\hline Histological grade & III $v s$. I-II & 39 vs. 31 & 19 vs. 15 & 1.05 & $0.51-2.17$ & 0.87 \\
\hline No. of positive nodes & $\geq 4$ vs. $0-3$ & 32 vs. 38 & 18 vs. 16 & 1.70 & $0.84-3.47$ & 0.14 \\
\hline Performance status & $1-2$ vs. 0 & $9 v s .61$ & $6 v s .28$ & 2.68 & $1.10-6.52$ & 0.030 \\
\hline $\mathrm{Age}^{\wedge}$ & & & & 1.01 & $0.97-1.05$ & 0.56 \\
\hline
\end{tabular}

No.: Number, HR: hazard ratio, CI: confidence interval. ^continuous variable. *Firth’s correction was applied for rare events.

tumors who received perioperative chemotherapy. In contrast, patients with MMR-proficient (pMMR) tumors benefited from perioperative chemotherapy (31). A limitation of our study is that all patients received adjuvant therapy post-surgery, and therefore the lack of difference in survival between the dMMR and pMMR groups may be due to the detrimental effect of adjuvant therapy in the dMMR patients and its beneficial effect in the pMMR patients. Separate from and in addition to microsatellite instability, high tumor mutational burden is emerging as a potential predictive biomarker of response to immune checkpoint inhibition (32). Mutations can give rise to neoantigens that can be recognized and targeted by the immune system. Treatment with immune checkpoint inhibitors can further enhance the immune response against hypermutated tumors. Although we evaluated mutations in a limited panel of genes, we found a significant correlation between the presence of mutations and the intratumoral CD8 TIL density, suggesting that immune checkpoint blockade may be an effective adjuvant treatment for patients with resected gastric cancer with high mutational burden. 
A

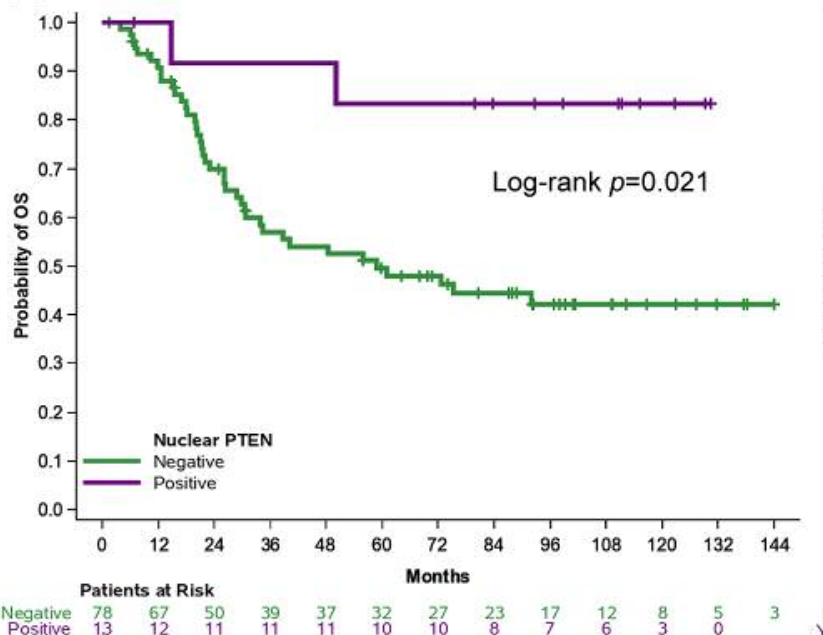

B

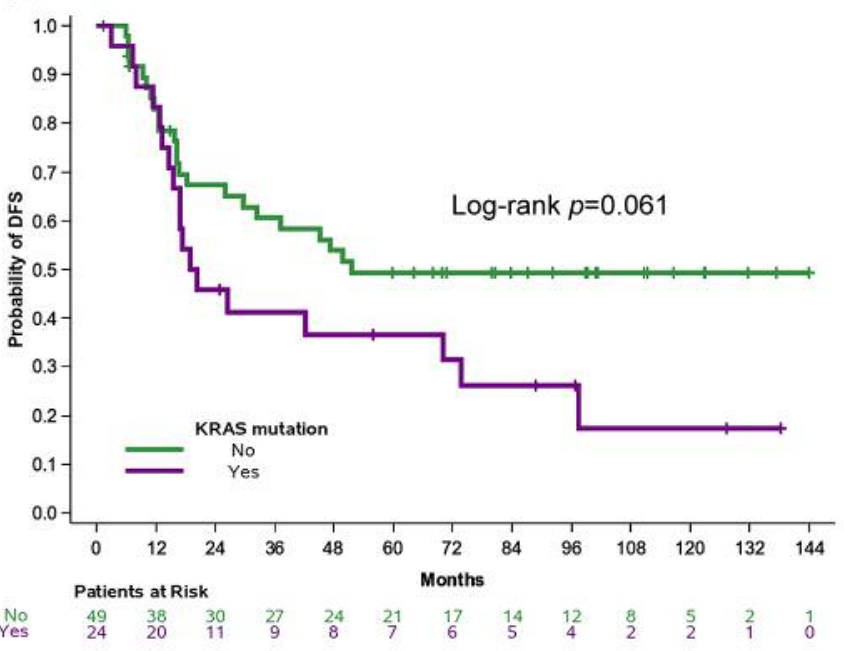

C

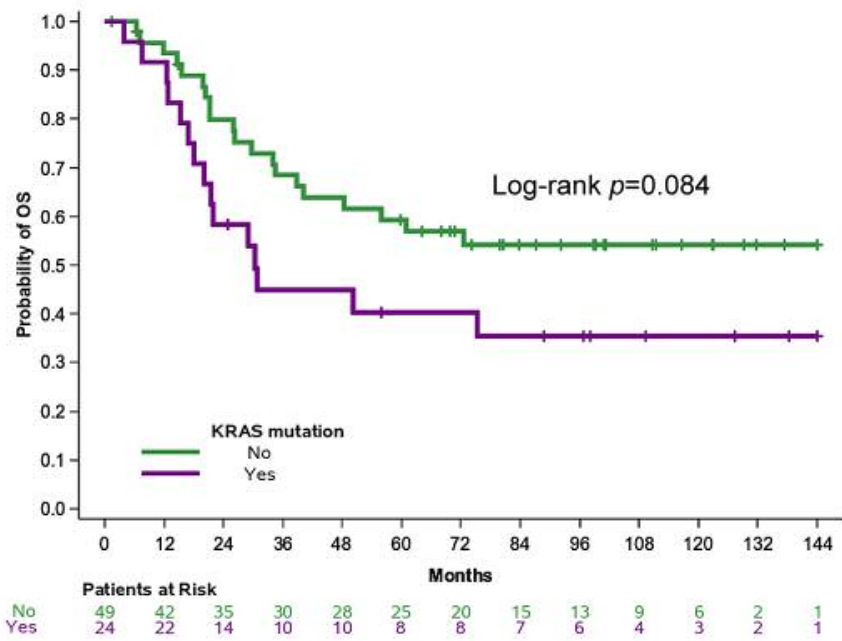

Figure 5. Kaplan-Meier plots of overall survival (OS) by PTEN expression, and disease-free survival (DFS) and overall survival (OS) by KRAS mutation status. A. PTEN-positive tumors were associated with longer OS (HR=0.27; Wald's $p=0.046)$. B. For patients with KRAS mutant tumors, we observed a trend associated with shorter DFS. C. A similar trend associated with shorter OS was also observed for patients with KRAS mutant tumors, compared to KRAS wild-type tumors.

We further showed that none of the HER2-positive tumors in our cohort harbored a KRAS mutation. This finding is in keeping with TCGA data that showed that a mutual exclusivity between ERBB2 amplification and KRAS mutation (24). As both KRAS mutations and HER2 overexpression activate the MAPK pathway, they subsequently promote cancer cell growth, invasion and metastasis $(33,34)$. In contrast, in colon cancer, EGFR expression co-occurs with KRAS mutation (35), and mutations in KRAS predict for resistance to anti-EGFR therapy (36). Based on the results of our study and others (24, $37,38)$, it seems that $K R A S$ mutations do not play a role in the resistance to HER2-directed therapy in gastric cancer, since these features seem to be mutually exclusive. Additionally, we found a significant association between the presence of PIK3CA mutations and VEGFA protein expression. Studies have demonstrated that the activation of the PI3K pathway results in increased expression of the hypoxia-inducible factor$1 \alpha$ (HIF-1 $\alpha)$ protein, HIF- $1 \alpha$ transcriptional activity and expression of VEGF (39-41). Further, inhibition of the PI3K pathway with the pan-PI3K small molecule inhibitor LY294002 suppresses VEGF transcription and protein expression, and therefore inhibits angiogenesis and tumor growth $(41,42)$. These findings suggest that combined inhibition of PI3K and angiogenesis may be synergistic and warrants further evaluation in the treatment of PIK3CA mutant gastric cancer. 
Lastly, we investigated the potential prognostic significance of these genetic and protein biomarkers in operable gastric adenocarcinoma. We found that the association between KRAS mutations and inferior clinical outcomes, both DFS and OS, trended toward significance. Although KRAS mutations have been shown to confer poor prognosis in colorectal cancer (43-45), its role in gastric cancer is less clear. Matsusaka and colleagues showed that $K R A S$ mutations were predictors of inferior survival in patients with metastatic gastric cancer treated with platinumbased therapy (46), while Warneke and colleagues showed similar results in a cohort of patients with stage I-IV gastric cancer (47). However, other studies have demonstrated disparate results, ranging from lack of association between $K R A S$ mutations and survival in resected gastric cancer (48) to a high prevalence of KRAS mutations in a group of patients with favorable prognosis (49). Even though KRAS, for the most part, remains undruggable, several treatment strategies targeting the MAPK pathway, including MEK, ERK and SHP2 inhibitors, are currently being investigated in KRAS mutant tumors. While our results need further validation, it is possible that these patients may benefit from novel adjuvant treatment approaches targeting the MAPK pathway, rather than traditional fluorouracil-based adjuvant chemotherapy.

Additionally, of all immunohistochemical biomarkers we studied, only loss of nuclear PTEN expression was associated with inferior OS. Indeed, loss of PTEN expression has been shown to be a poor prognostic marker in several malignancies, including breast, prostate and non-small cell lung cancer (5052). Furthermore, cytoplasmic PTEN loss has also been associated with worse outcomes in gastric cancer $(20,53,54)$. However, to our knowledge, this is the first study to demonstrate a correlation between nuclear PTEN loss and inferior OS in operable gastric cancer. While the role of cytoplasmic PTEN as a negative regulator of the PI3K/AKT pathway has been well described, its nuclear function needs further elucidation. However, there are emerging data that nuclear PTEN downregulates the MAPK pathway and decreases cyclin D1 expression inducing G0-G1 arrest (55), but also enhances DNA repair and thus maintains chromosomal stability (56) and enhances apoptosis (57). Despite the limitations of our small sample size, we showed that patients whose tumors exhibited loss of nuclear PTEN expression experienced shorter OS compared to patients with intact PTEN expression in their tumors. Given the poor outcomes of these patients despite adjuvant chemoradiotherapy, it would be reasonable to consider intensification of adjuvant therapy and testing of novel agents that target the MAPK pathway, block the cell cycle or induce apoptosis.

Our study has certain limitations. A major limitation is its small sample size, which may have obscured the prognostic significance of certain genetic or protein biomarkers. Additional limitations include the retrospective nature of our study and the lack of a control group of patients treated with surgery alone, that would allow the identification of biomarkers predictive of response or resistance to adjuvant chemoradiotherapy.

In summary, we evaluated a large panel of genetic and protein biomarkers in a cohort of patients with gastric cancer who underwent surgery and adjuvant chemoradiotherapy. We demonstrated that EBV-positive tumors and tumors with mutations in cancer-associated genes had increased CD8 TIL density. We further showed that PIK3CA mutations are associated with increased VEGFA protein expression, an association that may inform treatment strategies for gastric cancer patients. Lastly, we found that the presence of KRAS mutations and loss of nuclear PTEN expression are associated with inferior OS. This finding, if validated, may have significant implications for the prognostic classification of operable gastric cancer and could identify patients who would benefit from intensification of adjuvant therapy or novel treatment strategies to prevent recurrence.

\section{Conflicts of Interest}

The Authors declare no conflicts of interest in regard to this study.

\section{Authors' Contributions}

Conceptualization: EP, IC, VK, DP, GF. Methodology: VK, KP, EG, MB, SC. Formal Analysis: GAK. Investigation: KP, EG, MB, AF. Resources: VGG, MB, CP, DP, GF. Supervision: EP, VK, GF. Writing/editing: EP, IC, VK, GAK, KP, MB, SC. Writing/review and editing: All Authors.

\section{Acknowledgements}

The Authors are indebted to all patients and their families for their trust and participation in the HeCOG trials and for the provision of biological material for research purposes. The Authors wish to thank Ms Emily Daskalaki for excellent technical assistance with NGS and for NGS library construction; Ms Helen Sgouramalli, MSc for block sectioning and Ms Maria Moschoni for data coordination. Part of this work has been presented to ESMO 2018 Congress.

\section{Funding}

This study was supported by an internal Hellenic Cooperative Oncology Group (HeCOG) translational research grant (HE 7R/09). The funders played no role in study design, data collection and analysis, decision to publish, or preparation of the manuscript.

\section{References}

1 Ferlay J, Soerjomataram I, Dikshit R, Eser S, Mathers C, Rebelo M, Parkin DM, Forman D and Bray F: Cancer incidence and mortality worldwide: Sources, methods and major patterns in globocan 2012. Int J Cancer 136(5): E359-386, 2015. PMID: 252202842. DOI: $10.1002 / \mathrm{ijc} .29210$ 
2 Hundahl SA, Phillips JL and Menck HR: The national cancer data base report on poor survival of U.S. Gastric carcinoma patients treated with gastrectomy: Fifth edition american joint committee on cancer staging, proximal disease, and the "different disease" hypothesis. Cancer 88(4): 921-932, 2000. PMID: 10679663.

3 Pasini F, Fraccon AP and G DEM: The role of chemotherapy in metastatic gastric cancer. Anticancer Res 31(10): 3543-3554, 2011. PMID: 21965776.

4 Otowa Y, Okamoto S, Fujinaka R, Arai K, Murata K, Mii Y, Kakinoki K, Oka S and Kuroda D: Feasibility and effectiveness of gastrectomy for elderly gastric cancer patients. In Vivo 33(4): 1307-1311, 2019. PMID: 31280223. DOI: 10.21873/ invivo.11604

5 Macdonald JS, Smalley SR, Benedetti J, Hundahl SA, Estes NC, Stemmermann GN, Haller DG, Ajani JA, Gunderson LL, Jessup JM and Martenson JA: Chemoradiotherapy after surgery compared with surgery alone for adenocarcinoma of the stomach or gastroesophageal junction. N Engl J Med 345(10): 725-730, 2001. PMID: 11547741 . DOI: $10.1056 /$ NEJMoa010187

6 Cunningham D, Allum WH, Stenning SP, Thompson JN, Van de Velde CJ, Nicolson M, Scarffe JH, Lofts FJ, Falk SJ, Iveson TJ, Smith DB, Langley RE, Verma M, Weeden S, Chua YJ and Participants MT: Perioperative chemotherapy versus surgery alone for resectable gastroesophageal cancer. N Engl J Med 355(1): 1120, 2006. PMID: 16822992. DOI: 10.1056/NEJMoa055531

7 Lee J, Lim DH, Kim S, Park SH, Park JO, Park YS, Lim HY, Choi MG, Sohn TS, Noh JH, Bae JM, Ahn YC, Sohn I, Jung SH, Park CK, Kim KM and Kang WK: Phase iii trial comparing capecitabine plus cisplatin versus capecitabine plus cisplatin with concurrent capecitabine radiotherapy in completely resected gastric cancer with d2 lymph node dissection: The artist trial. J Clin Oncol 30(3): 268-273, 2012. PMID: 22184384. DOI: 10.1200/JCO.2011.39.1953

8 Bang YJ, Kim YW, Yang HK, Chung HC, Park YK, Lee KH, Lee KW, Kim YH, Noh SI, Cho JY, Mok YJ, Kim YH, Ji J, Yeh TS, Button P, Sirzen F, Noh SH and investigators Ct: Adjuvant capecitabine and oxaliplatin for gastric cancer after $\mathrm{d} 2$ gastrectomy (classic): A phase 3 open-label, randomised controlled trial. Lancet 379(9813): 315-321, 2012. PMID: 22226517. DOI: $10.1016 /$ S0140-6736(11)61873-4

9 Shu S, Iimori M, Nakanishi R, Jogo T, Saeki H, Oki E and Maehara Y: Changes in her2 expression and amplification status following preoperative chemotherapy for gastric cancer. In Vivo 32(6): 14911498, 2018. PMID: 30348707.DOI: 10.21873/invivo.11405

10 Pietrantonio F, De Braud F, Da Prat V, Perrone F, Pierotti MA, Gariboldi M, Fanetti G, Biondani P, Pellegrinelli A, Bossi I and Di Bartolomeo M: A review on biomarkers for prediction of treatment outcome in gastric cancer. Anticancer Res 33(4): 12571266, 2013. PMID: 23564763.

11 Kononen J, Bubendorf L, Kallioniemi A, Barlund M, Schraml P, Leighton S, Torhorst J, Mihatsch MJ, Sauter G and Kallioniemi OP: Tissue microarrays for high-throughput molecular profiling of tumor specimens. Nat Med 4(7): 844-847, 1998. PMID: 9662379. DOI: $10.1038 / \mathrm{nm} 0798-844$

12 Skacel M, Skilton B, Pettay JD and Tubbs RR: Tissue microarrays: A powerful tool for high-throughput analysis of clinical specimens: A review of the method with validation data. Appl Immunohistochem Mol Morphol 10(1): 1-6, 2002. PMID: 11893029. DOI: 10.1097/00129039-200203000-0000
13 Weiss LM and Chen YY: Eber in situ hybridization for epsteinbarr virus. Methods Mol Biol 999: 223-230, 2013. PMID: 23666702. DOI: 10.1007/978-1-62703-357-2_16

14 Detre S, Saclani Jotti G and Dowsett M: A “quickscore" method for immunohistochemical semiquantitation: Validation for oestrogen receptor in breast carcinomas. J Clin Pathol 48(9): 876-878, 1995. PMID: 7490328. DOI: 10.1136/jcp.48.9.876.

15 Petrini I, Lencioni M, Vasile E, Fornaro L, Belluomini L, Pasquini G, Ginocchi L, Caparello C, Musettini G, Vivaldi C, Caponi S, Ricci S, Proietti A, Fontanini G, Naccarato AG, Nardini V, Santi $S$ and Falcone A: Egfr and akt1 overexpression are mutually exclusive and associated with a poor survival in resected gastric adenocarcinomas. Cancer Biomark 21(3): 731-741, 2018. PMID: 29278885. DOI: 10.3233/CBM-170865

16 Chang H, Jung WY, Kang Y, Lee H, Kim A and Kim BH: Expression of ror1, pakt, and pcreb in gastric adenocarcinoma. Ann Diagn Pathol 19(5): 330-334, 2015. PMID: 26245996. DOI: 10.1016/j.anndiagpath.2015.06.010

17 Fondevila C, Metges JP, Fuster J, Grau JJ, Palacin A, Castells A, Volant A and Pera M: P53 and vegf expression are independent predictors of tumour recurrence and survival following curative resection of gastric cancer. Br J Cancer 90(1): 206-215, 2004. PMID: 14710231. DOI: 10.1038/sj.bjc. 6601455

18 Cao GD, Xu XY, Zhang JW, Chen B and Xiong MM: Phosphorylated mammalian target of rapamycin p-mtor is a favorable prognostic factor than mtor in gastric cancer. PLoS One 11(12): e0168085, 2016. PMID: 28005970. DOI: 10.1371/journal.pone. 0168085

19 Lee BL, Lee HS, Jung J, Cho SJ, Chung HY, Kim WH, Jin YW, Kim CS and Nam SY: Nuclear factor-kappab activation correlates with better prognosis and akt activation in human gastric cancer. Clin Cancer Res 11(7): 2518-2525, 2005. PMID: 15814628. DOI: $10.1158 / 1078-0432$.CCR-04-1282

20 Badary DM, Abdel-Wanis ME, Hafez MZ and Aboulhagag NA: Immunohistochemical analysis of pten, her2/neu, and ki67 expression in patients with gastric cancer and their association with survival. Pathophysiology 24(2): 99-106, 2017. PMID: 28262306. DOI: 10.1016/j.pathophys.2017.02.006

21 Gryko M, Kisluk J, Cepowicz D, Zinczuk J, Kamocki Z, Guzinska-Ustymowicz K, Pryczynicz A, Czyzewska J, Kemona A and Kedra B: Expression of insulin-like growth factor receptor type 1 correlate with lymphatic metastases in human gastric cancer. Pol J Pathol 65(2): 135-140, 2014. PMID: 25119174. DOI: $10.5114 /$ pjp.2014.42678

22 Fountzilas E, Kotoula V, Tikas I, Manousou K, Papadopoulou K, Poulios C, Karavasilis V, Efstratiou I, Pectasides D, Papaparaskeva K, Varthalitis I, Christodoulou C, Papatsibas G, Chrisafi S, Glantzounis GK, Psyrri A, Aravantinos G, Koliou GA, Koukoulis GK, Pentheroudakis GE and Fountzilas G: Prognostic significance of tumor genotypes and cd8+ infiltrates in stage I-III colorectal cancer. Oncotarget 9(86): 35623-35638, 2018. PMID: 30479693. DOI: 10.18632/oncotarget.26256

23 Lazaridis G, Lambaki S, Karayannopoulou G, Eleftheraki AG, Papaspirou I, Bobos M, Efstratiou I, Pentheroudakis G, Zamboglou N and Fountzilas G: Prognostic and predictive value of p-akt, egfr, and p-mtor in early breast cancer. Strahlenther Onkol 190(7): 636-638, 640-635, 2014. PMID: 24658605. DOI: $10.1007 / \mathrm{s} 00066-014-0620-6$ 
24 The Cancer Genome Atlas Research Network: Comprehensive molecular characterization of gastric adenocarcinoma. Nature 513(7517): 202-209, 2014. PMID: 25079317. DOI: 10.1038/ nature 13480

25 Fountzilas G, Giannoulatou E, Alexopoulou Z, Zagouri F, Timotheadou E, Papadopoulou K, Lakis S, Bobos M, Poulios C, Sotiropoulou M, Lyberopoulou A, Gogas H, Pentheroudakis G, Pectasides D, Koutras A, Christodoulou C, Papandreou C, Samantas E, Papakostas P, Kosmidis P, Bafaloukos D, Karanikiotis C, Dimopoulos MA and Kotoula V: Tp53 mutations and protein immunopositivity may predict for poor outcome but also for trastuzumab benefit in patients with early breast cancer treated in the adjuvant setting. Oncotarget 7(22): 32731-32753, 2016. PMID: 27129168. DOI: 10.18632/oncotarget.9022

26 Cho J, Chang YH, Heo YJ, Kim S, Kim NK, Park JO, Kang WK, Lee $\mathbf{J}$ and Kim KM: Four distinct immune microenvironment subtypes in gastric adenocarcinoma with special reference to microsatellite instability. ESMO Open 3(3): e000326, 2018. PMID: 29636988. DOI: 10.1136/esmoopen-2018-000326

27 De Rosa S, Sahnane N, Tibiletti MG, Magnoli F, Vanoli A, Sessa $\mathrm{F}$ and Chiaravalli AM: $\operatorname{Ebv}(+)$ and msi gastric cancers harbor high pd-11/pd-1 expression and high cd8(+) intratumoral lymphocytes. Cancers (Basel) 10(4), 2018. PMID: 29614789. DOI: $10.3390 /$ cancers 10040102

28 Shin SJ, Kim SY, Choi YY, Son T, Cheong JH, Hyung WJ, Noh SH, Park CG and Kim HI: Mismatch repair status of gastric cancer and its association with the local and systemic immune response. Oncologist 24(9): e835-e844, 2019. PMID: 30894409. DOI: 10.1634/theoncologist.2018-0273

29 Kim ST, Cristescu R, Bass AJ, Kim KM, Odegaard JI, Kim K, Liu XQ, Sher X, Jung H, Lee M, Lee S, Park SH, Park JO, Park YS, Lim HY, Lee H, Choi M, Talasaz A, Kang PS, Cheng J, Loboda A, Lee J and Kang WK: Comprehensive molecular characterization of clinical responses to pd-1 inhibition in metastatic gastric cancer. Nat Med 24(9): 1449-1458, 2018. PMID: 30013197. DOI: 10.1038/s41591-018-0101-z

30 Petrelli F, Ghidini M, Cabiddu M, Pezzica E, Corti D, Turati L, Costanzo A, Varricchio A, Ghidini A, Barni S and Tomasello G: Microsatellite instability and survival in stage ii colorectal cancer: A systematic review and meta-analysis. Anticancer Res 39(12): 6431-6441, 2019. PMID: 31810907. DOI: 10.21873 /anticanres.13857

31 Smyth EC, Wotherspoon A, Peckitt C, Gonzalez D, HulkkiWilson S, Eltahir Z, Fassan M, Rugge M, Valeri N, Okines A, Hewish M, Allum W, Stenning S, Nankivell M, Langley R and Cunningham D: Mismatch repair deficiency, microsatellite instability, and survival: An exploratory analysis of the medical research council adjuvant gastric infusional chemotherapy (magic) trial. JAMA Oncol 3(9): 1197-1203, 2017. PMID: 28241187. DOI: 10.1001/jamaoncol.2016.6762

32 Chan TA, Yarchoan M, Jaffee E, Swanton C, Quezada SA, Stenzinger A and Peters S: Development of tumor mutation burden as an immunotherapy biomarker: Utility for the oncology clinic. Ann Oncol 30(1): 44-56, 2019. PMID: 30395155. DOI: 10.1093/annonc/mdy495

33 Scheffzek K, Ahmadian MR, Kabsch W, Wiesmuller L, Lautwein A, Schmitz F and Wittinghofer A: The ras-rasgap complex: Structural basis for gtpase activation and its loss in oncogenic ras mutants. Science 277(5324): 333-338, 1997. PMID: 9219684.
34 Hou F, Shi DB, Chen YQ and Gao P: Human epidermal growth factor receptor-2 promotes invasion and metastasis in gastric cancer by activating mitogen-activated protein kinase signaling. Appl Immunohistochem Mol Morphol 27(7): 529-534, 2019. PMID: 9219684. DOI: 10.1097/PAI.0000000000000672

35 Huang CW, Tsai HL, Chen YT, Huang CM, Ma CJ, Lu CY, Kuo $\mathrm{CH}$, Wu DC, Chai CY and Wang JY: The prognostic values of egfr expression and kras mutation in patients with synchronous or metachronous metastatic colorectal cancer. BMC Cancer 13: 599, 2013. PMID: 24330663. DOI: 10.1186/1471-2407-13-599

36 Karapetis CS, Khambata-Ford S, Jonker DJ, O'Callaghan CJ, Tu D, Tebbutt NC, Simes RJ, Chalchal H, Shapiro JD, Robitaille S, Price TJ, Shepherd L, Au HJ, Langer C, Moore MJ and Zalcberg JR: K-ras mutations and benefit from cetuximab in advanced colorectal cancer. N Engl J Med 359(17): 1757-1765, 2008. PMID: 18946061. DOI: 10.1056/NEJMoa0804385

37 Pectasides E, Stachler MD, Derks S, Liu Y, Maron S, Islam M, Alpert L, Kwak H, Kindler H, Polite B, Sharma MR, Allen K, O’Day E, Lomnicki S, Maranto M, Kanteti R, Fitzpatrick C, Weber C, Setia N, Xiao SY, Hart J, Nagy RJ, Kim KM, Choi MG, Min BH, Nason KS, O'Keefe L, Watanabe M, Baba H, Lanman R, Agoston AT, Oh DJ, Dunford A, Thorner AR, Ducar MD, Wollison BM, Coleman HA, Ji Y, Posner MC, Roggin K, Turaga K, Chang P, Hogarth K, Siddiqui U, Gelrud A, Ha G, Freeman SS, Rhoades J, Reed S, Gydush G, Rotem D, Davison J, Imamura Y, Adalsteinsson V, Lee J, Bass AJ and Catenacci DV: Genomic heterogeneity as a barrier to precision medicine in gastroesophageal adenocarcinoma. Cancer Discov 8(1): 37-48, 2018. PMID: 28978556. DOI: 10.1158/2159-8290.CD-17-0395

38 Janjigian YY, Sanchez-Vega F, Jonsson P, Chatila WK, Hechtman JF, Ku GY, Riches JC, Tuvy Y, Kundra R, Bouvier N, Vakiani E, Gao J, Heins ZJ, Gross BE, Kelsen DP, Zhang L, Strong VE, Schattner M, Gerdes H, Coit DG, Bains M, Stadler ZK, Rusch VW, Jones DR, Molena D, Shia J, Robson ME, Capanu M, Middha S, Zehir A, Hyman DM, Scaltriti M, Ladanyi M, Rosen N, Ilson DH, Berger MF, Tang L, Taylor BS, Solit DB and Schultz $\mathrm{N}$ : Genetic predictors of response to systemic therapy in esophagogastric cancer. Cancer Discov 8(1): 49-58, 2018. PMID: 29122777. DOI: $10.1158 / 2159-8290 . C D-17-0787$

39 Mazure NM, Chen EY, Laderoute KR and Giaccia AJ: Induction of vascular endothelial growth factor by hypoxia is modulated by a phosphatidylinositol 3-kinase/akt signaling pathway in ha-rastransformed cells through a hypoxia inducible factor-1 transcriptional element. Blood 90(9): 3322-3331, 1997. PMID: 9345014.

40 Zhong H, Chiles K, Feldser D, Laughner E, Hanrahan C, Georgescu MM, Simons JW and Semenza GL: Modulation of hypoxia-inducible factor 1 alpha expression by the epidermal growth factor/phosphatidylinositol 3-kinase/pten/akt/frap pathway in human prostate cancer cells: Implications for tumor angiogenesis and therapeutics. Cancer Res 60(6): 1541-1545, 2000. PMID: 10749120.

41 Jiang BH, Zheng JZ, Aoki M and Vogt PK: Phosphatidylinositol 3-kinase signaling mediates angiogenesis and expression of vascular endothelial growth factor in endothelial cells. Proc Natl Acad Sci USA 97(4): 1749-1753, 2000. PMID: 10677529. DOI: 10.1073/pnas.040560897

$42 \mathrm{Hu} \mathrm{L}$, Hofmann J and Jaffe RB: Phosphatidylinositol 3-kinase mediates angiogenesis and vascular permeability associated with ovarian carcinoma. Clin Cancer Res 11(22): 8208-8212, 2005. PMID: 16299254. DOI: 10.1158/1078-0432.CCR-05-0206 
43 Taieb J, Zaanan A, Le Malicot K, Julie C, Blons H, Mineur L, Bennouna J, Tabernero J, Mini E, Folprecht G, Van Laethem JL, Lepage C, Emile JF and Laurent-Puig P: Prognostic effect of braf and kras mutations in patients with stage iii colon cancer treated with leucovorin, fluorouracil, and oxaliplatin with or without cetuximab: A post hoc analysis of the petacc- 8 trial. JAMA Oncol 2(5): 643-653, 2016. PMID: 26768652. DOI: 10.1001/jamaoncol.2015.5225

44 Taieb J, Le Malicot K, Shi Q, Penault-Llorca F, Bouche O, Tabernero J, Mini E, Goldberg RM, Folprecht G, Luc Van Laethem J, Sargent DJ, Alberts SR, Emile JF, Laurent Puig P and Sinicrope FA: Prognostic value of braf and kras mutations in msi and mss stage iii colon cancer. J Natl Cancer Inst 109(5), 2017. PMID: 28040692. DOI: 10.1093/jnci/djw272

45 Sideris M, Moorhead J, Diaz-Cano S, Haji A and Papagrigoriadis S: KRAS mutant status may be associated with distant recurrence in early-stage rectal cancer. Anticancer Res 37(3): 1349-1357, 2017. PMID: 28314302.

46 Matsusaka S, Kobunai T, Yamamoto N, Chin K, Ogura M, Tanaka G, Matsuoka K, Ishikawa Y, Mizunuma N and Yamaguchi T: Prognostic impact of KRAS mutant type and MET amplification in metastatic and recurrent gastric cancer patients treated with first-line s-1 plus cisplatin chemotherapy. Genes Cancer 7(1-2): 27-35, 2016. PMID: 27014419. DOI: 10.18632/genesandcancer.96

47 Warneke VS, Behrens HM, Haag J, Balschun K, Boger C, Becker T, Ebert MP, Lordick F and Rocken C: Prognostic and putative predictive biomarkers of gastric cancer for personalized medicine. Diagn Mol Pathol 22(3): 127-137, 2013. PMID: 23846438. DOI: 10.1097/PDM.0b013e318284188e

48 Okines AF, Gonzalez de Castro D, Cunningham D, Chau I, Langley RE, Thompson LC, Stenning SP, Saffery C, Barbachano Y, Coxon F, Middleton G, Ferry D, Crosby T, Madhusudan S, Wadsley J, Waters J, Hall M, Swinson D, Robinson A, Smith D, Reis-Filho JS, Waddell TS, Puckey L, Hulkki Wilson S, Eltahir $\mathrm{Z}$, Band $\mathrm{M}$ and Wotherspoon $\mathrm{A}$ : Biomarker analysis in oesophagogastric cancer: Results from the real3 and transmagic trials. Eur J Cancer 49(9): 2116-2125, 2013. PMID: 23481512. DOI: $10.1016 /$ j.ejca.2013.02.007

49 Bria E, Pilotto S, Simbolo M, Fassan M, de Manzoni G, Carbognin L, Sperduti I, Brunelli M, Cataldo I, Tomezzoli A, Mafficini A, Turri G, Karachaliou N, Rosell R, Tortora G and Scarpa A: Comprehensive molecular portrait using next generation sequencing of resected intestinal-type gastric cancer patients dichotomized according to prognosis. Sci Rep 6: 22982, 2016. PMID: 26961069. DOI: 10.1038/srep22982

50 Lazaridis G, Kotoula V, Vrettou E, Kostopoulos I, Manousou K, Papadopoulou K, Giannoulatou E, Bobos M, Sotiropoulou M, Pentheroudakis G, Efstratiou I, Papoudou-Bai A, Psyrri A, Christodoulou C, Gogas H, Koutras A, Timotheadou E, Pectasides D, Zagouri F and Fountzilas G: Opposite prognostic impact of single pten-loss and pik3ca mutations in early highrisk breast cancer. Cancer Genomics Proteomics 16(3): 195-206, 2019. PMID: 31018950 . DOI: $10.21873 / \operatorname{cgp} .20125$
51 Hamid AA, Gray KP, Huang Y, Bowden M, Pomerantz M, Loda $\mathrm{M}$ and Sweeney CJ: Loss of pten expression detected by fluorescence immunohistochemistry predicts lethal prostate cancer in men treated with prostatectomy. Eur Urol Oncol 2(5): 475-482, 2019. PMID: 31411988. DOI: 10.1016/j.euo.2018.09.003

52 Bepler G, Sharma S, Cantor A, Gautam A, Haura E, Simon G, Sharma A, Sommers E and Robinson L: Rrm1 and pten as prognostic parameters for overall and disease-free survival in patients with non-small-cell lung cancer. J Clin Oncol 22(10): 18781885, 2004. PMID: 15143080. DOI: 10.1200/JCO.2004.12.002

53 Kang HJ, Lee IS, Park YS, Ho WJ, Sohn D, Ahn JY, Yook JH and Kim BS: Biomarkers of ebv-positive gastric cancers: Loss of pten expression is associated with poor prognosis and nodal metastasis. Ann Surg Oncol 23(11): 3684-3692, 2016. PMID: 27221363. DOI: $10.1245 / \mathrm{s} 10434-016-5284-2$

54 Chiappini PBO, de Medeiros IUD, Lima LGC, Fregnani JH, Nonogaki S, da Costa WL Jr., Coimbra FJF, Silva M, de Mello CAL, Pinto CAL and Begnami MD: Prognostic implications of phosphatidylinositol 3-kinase/akt signaling pathway activation in gastric carcinomas. Arch Med Sci 13(6): 1262-1268, 2017. PMID: 29181056. DOI: 10.5114/aoms.2016.60394

55 Chung JH and Eng C: Nuclear-cytoplasmic partitioning of phosphatase and tensin homologue deleted on chromosome 10 (pten) differentially regulates the cell cycle and apoptosis. Cancer Res 65(18): 8096-8100, 2005. PMID: 16166282. DOI: 10.1158/0008-5472.CAN-05-1888

56 Shen WH, Balajee AS, Wang J, Wu H, Eng C, Pandolfi PP and Yin Y: Essential role for nuclear pten in maintaining chromosomal integrity. Cell 128(1): 157-170, 2007. PMID: 17218262. DOI: 10.1016/j.cell.2006.11.042

57 Gil A, Andres-Pons A, Fernandez E, Valiente M, Torres J, Cervera $\mathrm{J}$ and Pulido R: Nuclear localization of pten by a randependent mechanism enhances apoptosis: Involvement of an nterminal nuclear localization domain and multiple nuclear exclusion motifs. Mol Biol Cell 17(9): 4002-4013, 2006. PMID: 17218262. DOI: 10.1091/mbc.e06-05-0380.
Received January 22, 2020

Revised February 21, 2020

Accepted February 29, 2020 